\title{
Absence of domestic triatomine colonies in an area of the coastal region of Ecuador where Chagas disease is endemic
}

\author{
Mario J Grijalva ${ }^{1,2}{ }^{+}$, Francisco S Palomeque ${ }^{2}$, Anita G Villacís ${ }^{2}$, Carla L Black ${ }^{3}$, Laura Arcos-Terán ${ }^{2}$ \\ 1Tropical Disease Institute, Biomedical Sciences Department, College of Osteopathic Medicine, \\ Ohio University, 333 Irvine Hall, Athens, Ohio 45701, OH, USA ${ }^{2}$ Center for Infectious Disease Research, School of Biological Sciences, \\ Pontifical Catholic University of Ecuador, Quito, Ecuador ${ }^{3}$ Department of Epidemiology, Gillings School of Global Public Health, \\ University of North Carolina, Chapel Hill, NC, USA
}

Rhodnius ecuadoriensis is considered the second most important vector of Chagas disease in Ecuador. It is distributed across six of the 24 provinces and occupies intradomiciliary, peridomiciliary and sylvatic habitats. This study was conducted in six communities within the coastal province of Guayas. Triatomine searches were conducted in domestic and peridomestic habitats and bird nests using manual searches, live-bait traps and sensor boxes. Synantrhopic mammals were captured in the domestic and peridomestic habitats. Household searches $(n=429)$ and randomly placed sensor boxes $(n=360)$ produced no live triatomine adults or nymphs. In contrast, eight nymphs were found in two out of six searched Campylorhynchus fasciatus (Troglodytidae) nests. Finally, Trypanosoma cruzi DNA was amplified from the blood of $10 \%$ of the 115 examined mammals. Environmental changes in land use (intensive rice farming), mosquito control interventions and lack of intradomestic adaptation are suggested among the possible reasons for the lack of domestic triatomine colonies.

Key words: Chagas disease - Ecuador - Rhodnius ecuadoriensis - Campylorhynchus fasciatus - sylvatic

Chagas disease affects an estimated 230,000 people in Ecuador (PAHO 2006). The coastal area, and in particular the province of Guayas, has been considered the area with the highest prevalence rates (Lent \& León 1958, Aguilar et al. 1999, WHO 2002). Triatoma dimidiata and Rhodnius ecuadoriensis are considered the major vectors of Chagas disease in this region (Abad-Franch et al. 2001, 2002, Villacís et al. 2008). It has been hypothesised that $T$. dimidiata was introduced by humans into coastal areas of Ecuador and Perú, most likely from Guatemala, Honduras and Nicaragua (Abad-Franch et al. 2001, Bargues et al. 2008). Its distribution has been reported from México to Northern Perú (Abad-Franch et al. 2001, Bargues et al. 2008, Dorn et al. 2009). On the other hand, $R$. ecuadoriensis is endemic and has been reported to be distributed in the coastal region (provinces of Santo Domingo de los Tsáchilas, Manabí, Guayas, Los Ríos and El Oro) and the southern inter-Andean valleys of province of Loja (Abad-Franch et al. 2001, 2002, Grijalva et al. 2005). In the central coastal region of Ecuador, sylvatic $R$. ecuadoriensis populations have been reported in association with the palm tree Phytelephas aequatorialis. This palm tree is part of the endemic vegetation, es-

Financial support: UNICEF/UNDP/World Bank/WHO/TDR, Ohio University College of Osteopathic Medicine, Pontifical Catholic University of Ecuador, Children's Heartlink, Plan International Ecuador, Ecuadorian Ministry of Public Health (PNCha/SNEM)

+ Corresponding author: grijalva@oucom.ohiou.edu

Received 15 December 2009

Accepted 13 May 2010 pecially in the provinces of Manabí and Santo Domingo de los Tsáchilas (Villacís et al. 2008), and is widely exploited for its seeds, locally known as tagua, which are used for food and handycrafts and for its fronds, used in the traditional construction of thatch roofs (Henderson et al. 1995, Southgate 1997, Abad-Franch et al. 2001, 2005). P. aequatorialis cannot be cultivated due to its slow growth and its apparent need of original surrounding vegetation to germinate (Velásquez Runk 1998). In the province of El Oro, where this palm tree is less abundant, $R$. ecuadoriensis are found in peridomestic and intradomestic habitats, where invasions and colonizations by this species of triatomine are frequent (Abad-Franch et al. 2001, Cuba Cuba et al. 2002). In regions outside of the distribution of $P$. aequatorialis, such as province of Loja (southern highlands) and in northern Perú, R. ecuadoriensis is found primarily in the domicile and peridomicile (Abad-Franch et al. 2001, Cuba Cuba et al. 2002, Grijalva et al. 2005). However, Grijalva and Villacís (2009) recently reported sylvatic infestations of $R$. ecuadoriensis in nests of Sciurus stramineus in the province of Loja. Moreover, R. ecuadoriensis has been found in Elaeis guineensis or oil palm in the province of Los Ríos (Cuba Cuba et al. 2002); this plant is widely cultivated in the coastal and Amazon region of Ecuador.

In the last three decades, the northern province of Guayas has undergone important environmental changes in the use of the land. Among them, large-scale irrigation, flow control and the Daule-Peripa Hydroelectric Project have increased the ability of the land to be used for intensive farming of crops, such as rice, sugar cane, banana, coffee, cacao and cotton. However, there is little information about the ecological impact caused by this irrigation project (Twilley et al. 1998). The present paper reports the results of an entomological survey conducted 
in northern province of Guayas in the coastal region of Ecuador, which has been historically considered as a high Trypanosoma cruzi transmission area (WHO 2002).

\section{MATERIALS AND METHODS}

Study area - This study was carried out in six communities of province of Guayas during July 2003 (Figure). The research was conducted within the communities of Los Angeles [S01 46', W79 ${ }^{\circ} 58^{\prime} ; 18 \mathrm{~m}$ above sea level (masl)] and La Alegría (S01 ${ }^{\circ} 38^{\prime}, \mathrm{W} 80^{\circ} 00^{\prime}$; 30 masl), located in Santa Lucía county, Puerto Rico (S01³2', W7953'; 40 masl), Lomas de Colimes (S01 ${ }^{\circ} 34$, W80 $00^{\circ} ; 35$ masl) and San Antonio (S01 $36^{\prime}$, W80 $01^{\prime}$; 30 masl), located in Colimes county, and Macul (S01 36 ', W79 52'; 25 masl), located in Palestina county. This region has an average annual rainfall of $3000 \mathrm{~mm}$ and experiences a rainy season from January-May; the dry season is from June-December. The average high temperature is $36^{\circ} \mathrm{C}$ and the average low temperature is $18^{\circ} \mathrm{C}$ (INAMHI 2009). Agriculture is the most important economic activity, but the rearing of cattle and pigs is also common (Correa 2002).

Mapping, sampling, questionnaires and informed consent - The location of every domiciliary unit (DU) (defined as the area including the intra and peridomiciliary spaces) and all roads and trails within each community were recorded using geographical positioning system units (eTrex, Garmin, Kansas, USA). Maps were constructed using MapInfo 7.0 (MapInfo, New York, USA). All houses in the communities were visited.

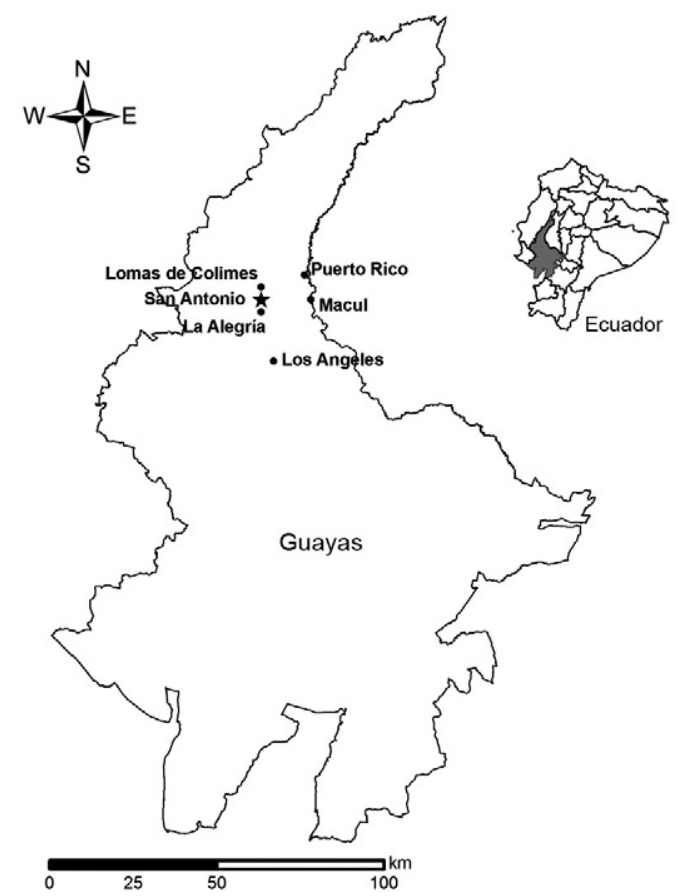

Map of province of Guayas, Ecuador, showing the location of the studied communities. Locality with presence of sylvatic Rhodnius ecuadoriensis (San Antonio) is indicated by an asterisk.
Informed consent was obtained from the head of the household, following Ohio University and Pontifical Catholic University of Ecuador Institutional Review Board policies for research involving human subjects. Construction features of each surveyed house and the presence of domestic animals were recorded and a questionnaire concerning knowledge, attitudes and practices (KAP) was administered.

Triatomine searches - Active intradomiciliary and peridomiciliary entomological searches for triatomines were conducted, using the one man-hour search method, as previously described (Grijalva et al. 2005). The entomological results obtained at the DUs prompted limited triatomine searches in birds' nests in areas approximately $200 \mathrm{~m}$ from DUs only in the communities of San Antonio and La Alegría. Approximately 10 birds' nests located in trees (Acacia macracantha) (Mimosaceae) and palm trees ( $P$. aequatorialis) and randomly chosen by field personnel were searched. The birds' nests were brought to the ground using $3 \mathrm{~m}$ wooden poles and were manually dissected on top of yellow plastic sheets. Livebait traps were also used for collection in sylvatic areas of San Antonio ( $\mathrm{n}=13)$ and La Alegría $(\mathrm{n}=10)$, as previously described by Noireau et al. (2002). Triatomines were collected and placed in labelled plastic containers. Then, the insects were taken to the insectary of the Center for Infectious Disease Research at the Catholic University of Ecuador to be counted and labelled. Taxonomic identification was done using the keys described by Lent and Wygodzinsky (1979). In addition, 360 sensor boxes constructed of black card stock forming a rectangular box ( $15 \mathrm{~cm}$ long, $8 \mathrm{~cm}$ wide and $2 \mathrm{~cm}$ deep) with an insect adhesive (Tangle-Trap Adhesive, Insect trap coating, Tanglefoot Company, Michigan, USA) spread inside the box were placed in sixty randomly selected houses, with six sensor boxes in each house: three in the peridomicile and three in the domicile, especially in chicken nests and under the beds. The boxes were checked weekly for one month by volunteer members of the communities under the supervision of a trained field entomologist.

Mammal collections and parasitological tests Mammals captured using Sherman and Tomahawk traps placed in the domicile and peridomicile were processed as previously described (Pinto et al. 2006). Trypanosoma spp infection was determined by direct microscopy and polymerase chain reaction using the S35/S36 primer pair (Vallejo et al. 1999).

\section{RESULTS}

Triatomine infestation - Eighty seven percent $(\mathrm{n}=$ 415) out of 477 houses visited were examined. No live triatomines were found in the domicile or peridomicile of the examined DUs. The only evidence of past triatomine invasion was found in San Antonio, where one dead adult $R$. ecuadoriensis was found caught in a spider web within the bedroom of one DU. One exuviae, probably a 4 th or 5th instar nymph, was found under the floor of the same DU, suggesting an apparent previous colonization. The walls of the infested DU were constructed with guadúa cane (Guadua angustifolia), the floor with wooden 
planks and the roof with zinc plates. No triatomines were captured with the sensor boxes. Live bait traps placed in two $P$. aequatorialis palm trees in the community of $\mathrm{La}$ Alegría were negative.

Bird nest searches - In the community of San Antonio, one adult and three 2 nd stage $R$. ecuadoriensis nymphs were found in two separate nests belonging to a fasciated wren (Campylorhynchus fasciatus; Passeriformes: Troglodytidae), locally known as charrascos. Both infested nests were found in the same tree, A. macracantha, locally known as guarángano. In addition, two 1st stage, one 2nd stage and one 4th stage nymphs were captured in live bait traps placed nearby in a cerezo tree (Crescentia cujete, Bignoniaceae). Subsequent sylvatic searches conducted in the communities of $\mathrm{La}$ Alegría and Macul were also negative.

Trypanosoma infection in mammals - The blood of a total of 115 mammals was analyzed parasitologically. Of these, $10.4 \%$ were determined to be infected with $T$. cruzi. No Trypanosoma rangeli were detected (Table).

Housing characteristics - Of the 477 total houses surveyed in Guayas, 59.3\% were constructed with walls made of cane, $47.4 \%$ had a latrine and $39.7 \%$ did not have any kind of toilet. Crowding, defined as more than three people sleeping per bedroom, was reported in $72 \%$ of DUs. Spraying with insecticides by the inhabitants within the past five years was reported in $37.6 \%$ of DUs (mean time $=3.2$ months prior to our visit), whereas $30.5 \%$ reported having been sprayed by the National Malaria Control Service within the last five years (mean time $=8.3$ months prior to our visit). The presence of

\section{TABLE}

Trypanosoma cruzi infection in blood from mammals collected in the province of Guayas, Ecuador

\begin{tabular}{lcc}
\hline Habitat and species & $\mathrm{n}$ & $\begin{array}{c}\text { Infection } \\
\%\end{array}$ \\
\hline Domicile & & \\
$\quad$ Aegialomys xantheolus & 1 & - \\
$\quad$ Mus musculus & 56 & 10.7 \\
$\quad$ Rattus rattus & 18 & 16.7 \\
$\quad$ Sigmodon peruanus & 2 & - \\
Subtotal & 77 & 11.7 \\
Peridomicile & & \\
$\quad$ Didelphis marsupialis & 26 & 11.5 \\
$\quad$ Mus musculus & 2 & - \\
$\quad$ Philander opossum & 1 & - \\
$\quad$ Proechimys decumanus & 2 & - \\
$\quad$ Rattus norvegicus & 4 & - \\
$\quad$ Rattus rattus & 3 & - \\
Subtotal & 38 & 10.4 \\
\hline Total & 115 & \\
\hline
\end{tabular}

trash around the house was observed in $48.4 \%$ of DUs, $20.5 \%$ stored firewood near or under the house and $79.9 \%$ reported having chickens or other fowl.

$K A P$ - Of the 1,108 respondants $\geq 10$ years of age who responded to the KAP questionnaire, $8 \%$ had ever heard about Chagas disease and only $2.8 \%$ could correctly indicate how it is transmitted. Conversely, $57 \%$ had heard of malaria and $33 \%$ could correctly describe how malaria is transmitted. When shown pictures of local triatomine species, $45 \%$ of respondents reported having seen them, $12 \%$ reported them as a bothersome pest and 3\% recalled being bitten by one. Among the 475 respondents that recognised triatomines, $68 \%$ identified Rhodnius spp and $25 \%$ recognised Triatoma spp. Of the people that recognized triatomines, $74 \%$ reported seeing bugs within the last year, mainly during the rainy season (66\%).

\section{DISCUSSION}

The number of triatomine species present in Ecuador reflects an ecological complexity, illustrated in the diversity of life zones that range from desert areas to pluvial forests (Abad-Franch et al. 2001). T. dimidiata and $R$. ecuadoriensis are considered the main vectors of Chagas disease in Ecuador. They are widely distributed in the coastal area, which has been considered endemic for Chagas disease since the 1950s (Moncayo 2003). Although T. dimidiata has been reported in seven of the 24 provinces in Ecuador (Abad-Franch et al. 2001) and was previously reported to be the most important vector in the province of Guayas (Defranc 1982), this species was not found during this study.

We found evidence of past $R$. ecuadoriensis invasion in only one DU and live triatomines were found only in some few of the birds nests searched. This is in contrast with previous reports that designate Chagas disease to be highly endemic in northern province of Guayas (J Monroy, unpublished observations, Defranc 1982, Abad-Franch et al. 2001). However, in many areas of Ecuador, systematic studies have neither been conducted nor published. The low number of triatomines found in our study is in contrast with the parasitological analyses obtained from mammals collected at the same time, which are similar with the T. cruzi infection levels found in mammals in other areas endemic for Chagas disease, such as southern Ecuador (Pinto et al. 2006, Black et al. 2007, 2009).

Entomological searches conducted in sylvatic habitats in the neighbouring province of Manabí (Suarez-Davalos et al. 2010) and in the southern province of Loja (MJ Grijalva et al., unpublished observations) also found $R$. ecuadoriensis associated with $C$. fasciatus. This bird is conspicuous and small $(\sim 19 \mathrm{~cm})$, presenting with a grey colour and white stripes in the back and tail and a white with grey paunch. C. fasciatus usually eats insects; it constructs its nests high in the canopy of the trees. The nests are relatively large $(20 \times 40 \mathrm{~cm})$ and constructed with a loose weaving of straw, small branches and the remains of cloth or/and other materials. This bird belongs to the noisy group; it is found only in arid and semiarid areas of western Ecuador and Perú. In Ecuador, its range of distribution includes Manabí, Guayas, El Oro and Loja (Ridgely 
et al. 1989). Interestingly, recent studies have found an association between the Guayaquil squirrel (S. stramineus) and R. ecuadoriensis in Manabí and Loja (Grijalva \& Villacís 2009, Suarez-Davalos et al. 2010, MJ Grijalva et al., unpublished observations). Given the abundance of these vertebrate species in the province of Guayas and the profound effect that sylvatic triatomine populations could have in the long term effectiveness of Chagas disease control programs, systematic studies are needed in this region to determine the distribution of endemic triatomine species and their association with vertebrates.

Transmission of $T$. cruzi to people is a complex phenomenon that involves interplay between the parasites, vectors, reservoirs and humans. Environmental factors, native and introduced triatomine species, type of dwellings and other anthropogenic factors play important roles in creating optimal conditions for disease transmission (WHO 2002). Indeed, many studies have implicated housing characteristics as risk factors for infection with T. cruzi. However, despite similar housing conditions and socio-economic status, the seroprevalence of $T$. cruzi varies widely along the coast of Ecuador (Black et al. 2007). A seroprevalence survey conducted in Guayas in conjunction with the present study found an overall seroprevalence of $1 \%$, with a prevalence of $3 \%$ among subjects aged 60 years and older (Black et al. 2009). In contrast, the prevalence of T. cruzi seropositivity in the neighbouring coastal province of Manabí was $5.7 \%$, with prevalences reaching as high as $11 \%$ among subjects older than 60 years of age. The low seroprevalence reported in Guayas, particularly among young age groups as reported by Black et al. (2009), fits with the absent triatomine infestation found in this study.

Interestingly, despite the low infestation found, $44 \%$ of the respondents recognized the local triatomine species and $12 \%$ reported that the bugs were bothersome pests. It is possible that some of the respondents were not able to differentiate between triatomines and other reduviids. However, it is worth noting that $66 \%$ of those that recognized the bugs indicated seeing them during the rainy season. In contrast, our survey was conducted during the dry season (June/July). Although seasonal variations in triatomine density or movement in search of food or shelter could be expected, this alone is not enough to account for the absence of domestic infestation. Although the lack of adaptation to domestic habitats by $R$. ecuadoriensis in this area could not be dismissed, we hypothesized that the lack of $R$. ecuadoriensis infestation could be related to the indiscriminate use of insecticides in agricultural activities, particularly extensive rice farming, which is the most important economic activity in this region. In addition, malaria and dengue fever are endemic to this region, with thousands of cases of either disease being reported every year (PAHO 2008). Mosquitoes are reported by the population as a major nuisance. Mosquito abundance is increased by the fact that rice farming in this region is conducted in two yearly cycles, during the wet and rainy seasons, requiring plots to remain inundated with water for approximately 90-120 days. Moreover, the rainy season often is accompanied by flooding of the Daule and Perdido Rivers and their associated streams. Conversely, the need for water storage due to the lack of adequate drinking water distribution systems and the absence of sanitation infrastructure create artificial mosquito breeding sites during the dry season. For these reasons, insecticide is applied with some regularity by the Ministry of Health Malaria Control Service, using malathion and more frequently by the dwellers, using any available product that often includes remnants of agricultural products not indicated for intradomiciliary use.

The Andean Countries' Initiative for Chagas Disease Control aims to achieve the elimination of the introduced T. dimidiata populations in coastal Ecuador using chemical spraying and surveillance. However, the risk of $T$. cruzi transmission will continue afterwards due to the possibility of reinfestation by sylvatic triatomine species, such as R. ecuadoriensis (Guhl et al. 2009). Therefore, additional studies should be conducted in this region to better understand the distribution and ecology of endemic triatomine species and the implementation of an integral and coordinated insect control program that adds triatomine infestation surveillance to the existing mosquito control activities.

\section{ACKNOWLEDGEMENTS}

To Miguel Pinto, Mauricio Lascano, Sofia Ocaña-Mayorga, Alejandra Zurita and César Yumiseva, for technical assistance.

\section{REFERENCES}

Abad-Franch F, Aguilar HMV, Paucar AC, Lorosa ES, Noireau F 2002. Observations on the domestic ecology of Rhodnius ecuadoriensis (Triatominae). Mem Inst Oswaldo Cruz 97: 199-202.

Abad-Franch F, Palomeque FS, Aguilar HM 5th, Miles MA 2005. Field ecology of sylvatic Rhodnius populations (Heteroptera: Triatominae): risk factors for palm tree infestation in western Ecuador. Trop Med Int Health 10: 1258-1266.

Abad-Franch F, Paucar AC, Carpio CC, Cuba Cuba CA, Aguilar HMV, Miles MA 2001. Biogeography of Triatominae (Hemiptera: Reduviidae) in Ecuador: implications for the design of control strategies. Mem Inst Oswaldo Cruz 96: 611-620.

Aguilar HMV, Abad-Franch F, Racines VJ, Paucar AC 1999. Epidemiology of Chagas disease in Ecuador. A brief review. Mem Inst Oswaldo Cruz 94 (Suppl. I): 387-393.

Bargues MD, Klisiowicz DR, Gonzalez-Candelas F, Ramsey JM, Monroy C, Ponce C, Salazar-Schettino PM, Panzera F, Abad-Franch F, Sousa OE, Schofield CJ, Dujardin JP, Guhl F, Mas-Coma S 2008. Phylogeography and genetic variation of Triatoma dimidiata, the main Chagas disease vector in Central America, and its position within the genus Triatoma. PLoS Negl Trop Dis 2: e233.

Black CL, Ocaña-Mayorga S, Riner DK, Costales JA, Lascano MS, Arcos-Terán L, Preisser JS, Seed JR, Grijalva MJ 2009. Seroprevalence of Trypanosoma cruzi in rural Ecuador and clustering of seropositivity within households. Am J Trop Med Hyg 81: 1035-1040.

Black CL, Ocaña S, Riner D, Costales JA, Lascano MS, Davila S, Arcos-Teran L, Seed JR, Grijalva MJ 2007. Household risk factors for Trypanosoma cruzi seropositivity in two geographic regions of Ecuador. J Parasitol 93: 12-16.

Correa FJ 2002. Todo Guayas en sus manos, Universidad Espíritu Santo, Guayaquil, 11 pp. 
Cuba Cuba CA, Abad-Franch F, Roldán Rodríguez J, Vargas Vásquez F, Pollack Velásquez L, Miles MA 2002. The triatomines of northern Peru, with emphasis on the ecology and infection by trypanosomes of Rhodnius ecuadoriensis (Triatominae). Mem Inst Oswaldo Cruz 97: 175-183.

Defranc MI 1982. Enfermedad de Chagas, Casa de la Cultura Ecuatoriana, Núcleo del Guayas, Guayaquil, 275 pp.

Dorn PL, Calderon C, Melgar S, Moguel B, Solorzano E, Dumonteil E, Rodas A, de la Rua N, Garnica R, Monroy C 2009. Two distinct Triatoma dimidiata (Latreille, 1811) taxa are found in sympatry in Guatemala and Mexico. PLoS Negl Trop Dis 3: e393.

Grijalva MJ, Palomeque-Rodríguez FS, Costales JA, Davila S, Arcos-Teran L 2005. High household infestation rates by synanthropic vectors of Chagas disease in southern Ecuador. $J$ Med Entomol 42: 68-74.

Grijalva MJ, Villacís AG 2009. Presence of Rhodnius ecuadoriensis in sylvatic habitats in the southern highlands (Loja Province) of Ecuador. J Med Entomol 46: 708-711.

Guhl F, Pinto N, Aguilera G 2009. Sylvatic triatominae: a new challenge in vector control transmission. Mem Inst Oswaldo Cruz 104 (Suppl. I): 71-75.

Henderson A, Galeano G, Bernal R 1995. Field guide to the palms of the Americas, Princeton University Press, New York, 363 pp.

INAMHI - Instituto Nacional de Meteorología e Hidrología [homepage on the Internet]. Guayas: climatología: características generales del clima en la provincia del Guayas-Ecuador [updated 2009 Dec 15; cited 2009 Sep 07]. Available from: inamhi.gov.ec.

Lent H, León LA 1958. Um novo Rhodnius Stäl do Ecuador (Hemiptera: Reduviidae). Rev Bras Biol 18: 181-185.

Lent H, Wygodzinsky P 1979. Revision of the Triatominae (Hemiptera: Reduviidae) and their significance as vectors of Chagas' disease. Bull Am Mus Nat Hist 163: 123-520.

Moncayo A 2003. Chagas disease: current epidemiological trends after the interruption of vectorial and transfusional transmission in the Southern Cone countries. Mem Inst Oswaldo Cruz 98: 577-591.

Noireau F, Abad-Franch F, Valente SAS, Dias-Lima A, Lopes CM, Cunha V, Valente VC, Palomeque FS, Carvalho-Pinto CJ, Sherlock I, Aguilar M, Steindel M, Grisard EC, Jurberg J 2002. Trapping triatominae in silvatic habitats. Mem Inst Oswaldo Cruz 97: 61-63.
PAHO - Pan American Health Organization 2006. Technical report - Quantitative Chagas disease estimates, OPS/HDMCD/425-06, Montevideo, $28 \mathrm{pp}$.

PAHO - Pan American Health Organization 2008. 15a Reunión Interamericana a Nivel Ministerial en Salud y Agricultura. Equidad para atención de la salud: enfermedades postergadas en poblaciones olvidadas, Organización Panamericana de la Salud, Rio de Janeiro, $17 \mathrm{pp}$.

Pinto CM, Ocaña-Mayorga S, Lascano MS, Grijalva MJ 2006. Infection by trypanosomes in marsupials and rodents associated with human dwellings in Ecuador. J Parasitol 92: 1251-1255.

Ridgely RS, Tudor G, Brown WL 1989. The birds of South America: the oscine passerines, World Wildlife Fund, University of Texas Press, Austin, $70 \mathrm{pp}$.

Southgate D 1997. Alternatives for habitat protection and rural income generation. Document ENV-107, The Inter-American Development Bank, Washington DC, 54 pp.

Suarez-Davalos V, Dangles O, Villacís AG, Grijalva MJ 2010. Microdistribution of sylvatic triatomine populations in central-coastal Ecuador. J Med Entomol 47: 80-88.

Twilley RR, Gottfried RR, Rivera-Monroy VH, Zhang W, Montaño Armijos M, Bodero A 1998. An approach and preliminary model of integrating ecological and economic constraints of environmental quality in the Guayas River estuary, Ecuador. Environ Science \& Policy 1: 271-288.

Vallejo GA, Guhl F, Chiari E, Macedo AM 1999. Species specific detection of Trypanosoma cruzi and Trypanosoma rangeli in vector and mammalian host by polymerase chain reaction amplification of kinetoplast minicircle DNA. Acta Trop 72: 203-212.

Velásquez Runk J 1998. Productivity and sustainability of a vegetable ivory palm (Phytelephas aequatorialis, Arecaceae) under three management regimes in northwestern Ecuador. Economic Botany 52: 168-182.

Villacís AG, Arcos-Terán L, Grijalva MJ 2008. Life cycle, feeding and defecation patterns of Rhodnius ecuadoriensis (Lent \& León 1958) (Hemiptera: Reduviidae: Triatominae) under laboratory conditions. Mem Inst Oswaldo Cruz 103: 690-695.

WHO - World Health Organization 2002. Control of Chagas' disease. Second report of the WHO Expert Committee, WHO, Geneve, $107 \mathrm{pp}$. 